\title{
ANALISIS KINERJA PIPA KALOR LURUS MENGGUNAKAN SUMBU KAPILER SCREEN MESH 300 DENGAN MEMVARIASIKAN FILLING RASIO
}

\author{
Performance Analysis of Straight Heat Pipe Using Screen Mesh 300 Capillary \\ Wick by Varying Filling Ratios
}

Iwan Setyawan*, Sandy Reynaldy Riawan, Sri Poernomo Sari dan Ridwan

Jurusan Teknik Mesin, Universitas Gunadarma, Jalan Margonda Raya No. 100, Depok 16424, Indonesia

Informasi artikel

Diterima: $25 / 05 / 2020$

Direvisi : 02/06/2020

Disetujui: 24/06/2020

\begin{abstract}
Abstrak
Pipa kalor merupakan salah satu jenis pendingin yang memanfaatkan sistem dua fase yang memiliki kemampuan memindahkan kalor yang cukup tinggi. Perangkat ini tidak mengkonsumsi energi mekanik dan kinerja termal tergantung pada struktur sumbu. Tujuan penelitian ini adalah untuk membuat pipa kalor lurus tembaga dengan sumbu kapiler Screen Mesh 300 sebanyak 6 layer. Pada penelitian ini dilakukan pengujian dengan memvariasikan filling rasio, FR $40 \%, 60 \%$ dan $80 \%$. Pengambilan data diambil menggunakan data aquisition Labjack U6 Pro. Termokopel ditempatkan di beberapa titik kemudian diolah dengan sistem labview. Dari hasil penelitian, didapatkan temperatur steady evaporator tertinggi dengan Filling Rasio 40\% pada beban kalor 10W sampai $175 \mathrm{~W}$. Untuk FR $80 \%$ menghasilkan temperatur evaporator yang paling rendah pada beban kalor $10 \mathrm{~W}$ hingga $100 \mathrm{~W}$. Untuk beban kalor yang lebih tinggi $175 \mathrm{~W}$ hingga 275W, FR 60\% menghasikan temperature evaporator terendah diantara FR 40\% dan FR $80 \%$. Selanjutnya, tahanan termal pada FR $80 \%$ menghasilkan nilai terbesar untuk semua beban kalor. Sedangkan FR $60 \%$ menghasilkan tahanan termal yang hampir sama dengan dengan FR $80 \%$ untuk beban kalor $25 \mathrm{~W}$ hingga $275 \mathrm{~W}$. Namun demikian pada beban kalor $10 \mathrm{~W}, \mathrm{FR} 60 \%$ menghasilkan tahanan termal yang lebih rendah diantara FR40\% dan FR $80 \%$. Dengan demikian, dari hasil temperatur dan tahanan termal untuk pipa kalor dengan range beban kalor yang yang lebih luas, FR 60\% menghasilkan kinerja terbaik dibandingkan FR $80 \%$ dan FR $40 \%$.
\end{abstract}

Kata Kunci: filling rasio, kinerja, pipa kalor, screen mesh.

\begin{abstract}
The heat pipe is a type of cooling that utilizes a two-phase system that has the ability to move the heat quite high. This device does not consume mechanical energy and thermal performance depends on the wick structure. The purpose of this study was to create 6 layers of straight copper heat pipe with a Screen Mesh 300 capillary wick. In this study, testing by varying the filling ratio, $F R \quad 40 \%, 60 \%$ and $80 \%$. Retrieval of data taken using Labjack U6 Pro data aquisition. Thermocouples are placed at several points and then processed by the LabView system. From the results of the study, the highest evaporator temperature was obtained with FR $40 \%$ at heat loads of $10 \mathrm{~W}$ to $175 \mathrm{~W}$. For FR $80 \%$ produces the lowest evaporator temperature at heat loads of $10 \mathrm{~W}$ to $100 \mathrm{~W}$. For higher heat loads $175 \mathrm{~W}$ to $275 \mathrm{~W}$, FR $60 \%$ yields the lowest evaporator temperature between FR $40 \%$ and FR $80 \%$. Furthermore, thermal resistance at FR $80 \%$ produces the greatest value for all heat loads. Whereas FR 60\% produces thermal resistance which is almost the same as $F R \quad 80 \%$ for heat loads from $25 \mathrm{~W}$ to $275 \mathrm{~W}$. However, at a $10 \mathrm{~W}$ heat load, FR $60 \%$ produces lower thermal resistance between $F R 40 \%$ and FR $80 \%$. Thus, from the results of temperature and thermal resistance for heat pipes with a wider range of heat loads, FR $60 \%$ produces the best performance compared to FR $80 \%$ and FR $40 \%$.
\end{abstract}

Keywords: filling ratio, performance, heat pipe, screen mesh. 


\section{PENDAHULUAN}

Hampir seluruh produk teknologi yang menghasilkan fluks kalor pada proses operasionalnya, dilengkapi dengan sistem manajemen termal. Produk ini misalnya device elektronik, BTS, sistem pembangkit listrik ataupun teknologi baterai lithium (Putra dan Septiadi, 2014). Salah satu cara mengatur termal adalah penggunaan pipa kalor, dimana jenis ini merupakan salah satu jenis pendingin yang memanfaatkan sistem dua fase yang memiliki kemampuan memindahkan kalor yang cukup tinggi. Pendinginan dua fase terbukti menjadi solusi termal yang sangat efektif untuk system pendinginan dibandingkan dengan cairan satu fase (Setyawan, 2018).

Pipa kalor adalah perangkat pemindah kalor yang memiliki kemampuan pemindahan kalor yang tinggi. Perangkat ini tidak mengkonsumsi energi mekanik dan kinerja termal tergantung pada struktur sumbu, fluida kerja dan fluks panas yang diterapkan. Fenomena perubahan fasa fluida kerja memainkan dampak besar pada kinerja termalnya. Bagian evaporator pada pipa kalor digunakan untuk menyerap kalor. Penyerapan kalor mengakibatkan perubahan fase dari fluida kerja menjadi uap (Putra et al., 2016; Ramachandran et al., 2014). Pada pipa kalor berisi fluida kerja yang berfungsi sebagai fluida penghantar kalor dari ujung sisi panas (evaporator) ke ujung yang lain yaitu pendingin (kondensor). Secara umum, pipa kalor diproduksi menggunakan bahan logam yang kaku karena keuntungan dari pembuatan sederhana, konduksi panas tinggi dan kinerja kerja yang baik. Jenis bahan yang digunakan untuk membuat pipa tersebut biasanya terbuat dari aluminium, tembaga, dan tembaga berlapis nikel. Pada bagian dalam dinding pipa kalor tersebut berisi sumbu kapiler (wick) berupa sintered powder, screen mesh atau groove yang berfungsi sebagai jalur fluida dan pompa kapiler dari cairan. Mereka sering disebut sebagai "superkonduktor" kalor karena mereka memiliki kapasitas dan kecepatan perpindahan kalor yang luar biasa dengan hampir tidak ada kehilangan kalor (Huang et al., 2020; Zohuri, 2016).

Pipa kalor terdiri dari tiga bagian yaitu evaporator adiabatik dan kondensor. Evaporator berada pada salah satu ujungnya dimana panas diserap dan cairan diuapkan. Kemudian bagian adiabatik, dan kondensor yang terletak pada ujung lainnya dimana kalor dilepaskan. Sumbu kapiler digunakan untuk jalur cairan dari kondensor menuju evaporator. Cairan bergerak atas prinsip kerja kapiler. Setelah fluida menguap di bagian evaporator, maka uap tersebut mengalir menuju bagian kondensor. Selanjutnya mengalami penurunan suhu di kondensor sehingga uap merubah menjadi cairan. Selanjutnya cairan atau kondensat ini akan mengalir kembali ke sisi panas (evaporator) dan prosesnya akan berulang secara terus menuerus (Bumataria et al., 2019; Setyawan, 2018).

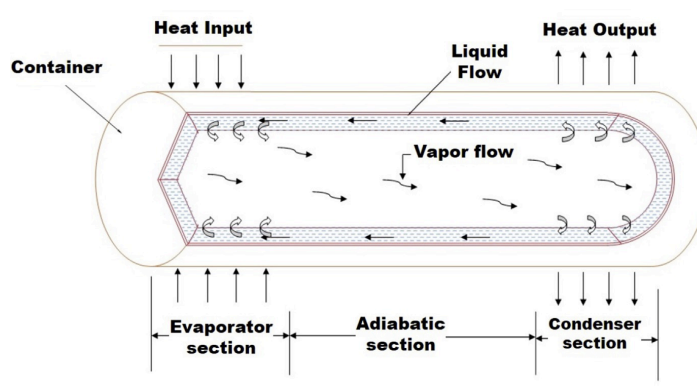

Gambar 1 Pipa Kalor

Prinsip fisika tekanan, termodinamika dan fluida menjadi dasar kerja pipa kalor dimana pada tekanan tertentu, cairan akan menguap sementara uap akan mencair pada temperatur tertentu (temperatur jenuh), sehingga akan terjadi pengaturan tekanan di dalam pipa kalor, pipa yang akan mengatur temperatur kerja dan terjadi perubahan fase dari cair ke uap dan uap ke cair (lihat gambar 1). Pada temperatur tertentu, jumlah energi panas yang diserap ketika cairan menguap akan sama dengan jumlah energi panas yang dilepaskan ketika uap berkondensasi (Wahyu, 2016).

Persamaan yang digunakan untuk menghitung filling rasio dan tahanan termal pada pipa kalor, adalah sebagai berikut:

\section{Filling Rasio}

Filling Rasio adalah rasio pengisisan fluida kerja di dalam pipa kalor yang diekspresikan sebagai rasio antara fluida kerja dengan volume evaporator (Faghri, 2014).

$$
F R=\frac{V l i q}{\text { Vevap }}
$$

Dimana, Vliq = Volume liquid yang dimasukan $(\mathrm{ml})$; Vevap = Volume evaporator $(\mathrm{ml})$.

\section{Tahanan Termal}

Secara umum tahanan termal (Thermal Resistance) dapat menggunakan persamaan berikut ini (Huang et al., 2020). 


$$
\text { Rth }=\frac{T e-T c}{Q}
$$

Dimana Rth $=$ Tahanan Termal $\left({ }^{\circ} \mathrm{C} / \mathrm{w}\right) ; \mathrm{Te}=$ Temperatur Evaporator $\left({ }^{\circ} \mathrm{C}\right)$; $\mathrm{TC}=$ Temperatur Condensor $\left({ }^{\circ} \mathrm{C}\right) ; \mathrm{Q}=$ Heat Load (Watt)

Persamaan ini digunakan mencari tahanan termal yang merupakan salah satu ukuran kinerja pipa kalor. Dimana pada penelitian ini akan menginvestigasi kinerja sebuah pipa kalor lurus yang dibuat dengan menggunakan sumbu kapiler screen mesh.

\section{METODOLOGI}

\section{Pembuatan Pipa Kalor Lurus}

Konsep rancangan pipa kalor lurus diterapkan seperti pipa kalor lurus pada umumnya. Pipa kalor ini terdiri dari pipa tembaga yang memiliki diameter $25,4 \mathrm{~mm}$ dengan tebal pipa $1 \mathrm{~mm}$ serta panjang 1500 $\mathrm{mm}$ sebagai kontainer dan sumbu kapiler menggunakan enam lapis screen mesh no 300. Screen mesh yang digunakan adalah no 300 dengan ukuran pori 44 micron.

Pada pembuatan kontatiner dilakukan dengan pemotongan pipa tembaga 1 inch dengan panjang $1.5 \mathrm{~m}$ menggunakan tubing cutter. Pada container ini terdapat tiga bagian yaitu evaporator, adiabatic dan kondensor dengan ukuran $500 \mathrm{~mm}$ masingmasing bagian seperti terlihat pada gambar 2. Pada bagian atas container diberi jalur khusus untuk pengukuran tekanan internal dan sebagai jalur untuk melakukan pemakuman pada sistem seperti terlihat pada gambar 3.

Pada bagian kondensor terdapat komponen pendingin yaitu water jacket. Terdapat pula sebuah inlet dan sebuah outlet yang berfungsi untuk keluar masuknya fluida pendingin. Fluida pendingin yang digunakan adalah air dengan temperatur ruangan. Suplai air berasal dari penampungan air berupa reservoir.

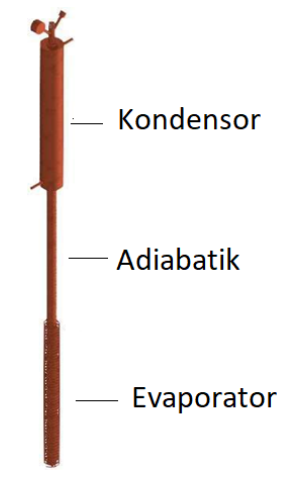

Gambar 2 Desain Pipa Kalor Lurus

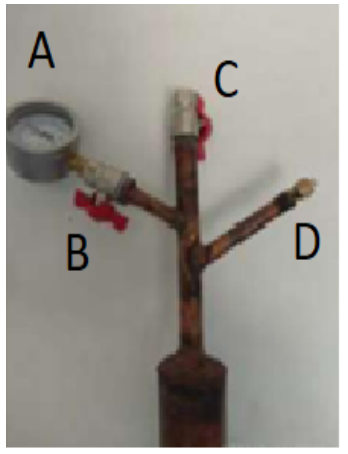

Keterangan:

A : Pressure gauge

compound

B : On-off valve

C : Valve untuk pengisian fluida kerja fluida

D : Nipple digunakan untuk jalur vakum

Gambar 3 Detail Pressure Gauge dan Jalur Vacuum

\section{Skematik Pengujian}

Skematik pengujian ditunjukkan pada gambar 4. Daya yang dimasukkan ke heater diatur oleh voltage regulator AC. Besarnya arus diukur dengan clamp meter. Kemudian coolant dari reservoir disrkulasikan pada kondenser dengan menggunakan pompa celup. Coolant dikondisikan pada temperature ruangan. Sedangkan laju aliran massa coolant diukur oleh rotameter. Pengukuran temperatur bagian yang penting pada alat eksperimen ini, menggunakan data aquisisi.

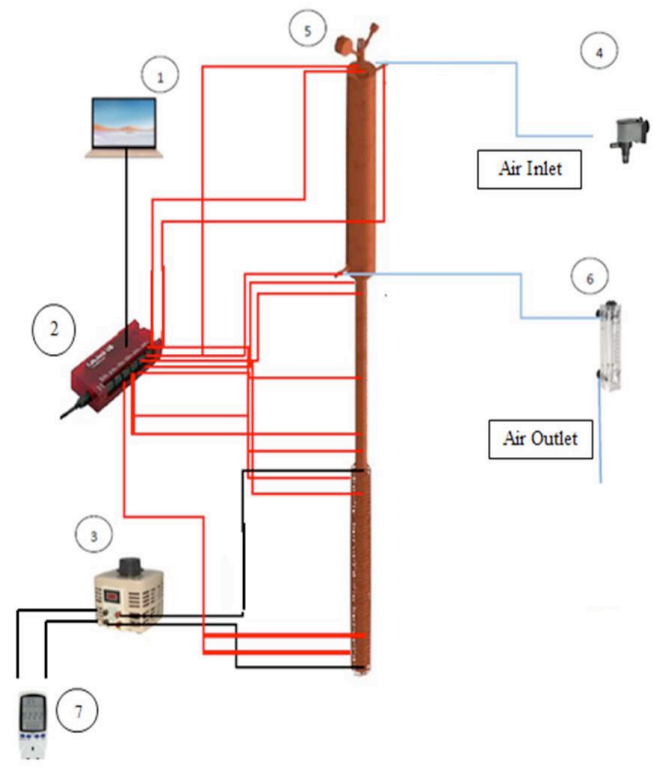

Keterangan:
1. Laptop
2. DAQ
3. AC voltage Regulator
4. Pompa Celup
5. Sistem Pengukur tekanan internal
6. Flow meter
7. Watt meter

Gambar 4 Skematik Pengujian 
Pengambilan data temperatur pipa kalor pengujian dilakukan pada 3 bagian utama yaitu Evaporator,Adiabatik dan Kondenser. Pengukuran dibagi menjadi 14 titik, dimana 6 titik pengukuran pada evaporator, 1 titik pada bagian adiabatic, 4 titik pada kondensor, dan 1 titik pada inlet dan 1 titik pada outlet serta 1 titik untuk linkungan sekitar. Untuk mencegah kebocoran kalor ke linkungan, maka alat eksperimen diisolasi menggunakan Rockwool. Pada pengujian ini, menggunakan fluida kerja aquades dengan variasi filling rasio $40 \%, 60 \%$ dan $80 \%$. Adapun beban kalor yang diberikan pada evaporator, divariasikan pada 10W, 25W, 50W, 100W, 175W dan 275W. Pada bagian Kondensor dialiri air coolan dengan suhu berkisar $28^{\circ} \mathrm{C}$ $30^{\circ} \mathrm{C}$ dengan debit aliran $150 \mathrm{ml} / \mathrm{menit}$.

\section{HASIL DAN PEMBAHASAN}

\section{Temperatur Evaporator}

Pada gambar 5, terlihat pada grafik bahwa ketika beban kalor diberikan, temperatur fluida kerja meningkat dengan cepat kemudian keadaan steady tercapai. Hal tersebut terjadi karena pada saat penyerapan kalor di evaporator, fluida kerja berubah fase menjadi uap. Selanjutnya uap bergerak menuju kondenser kemudian mengalami kondensasi pada Kondensor.

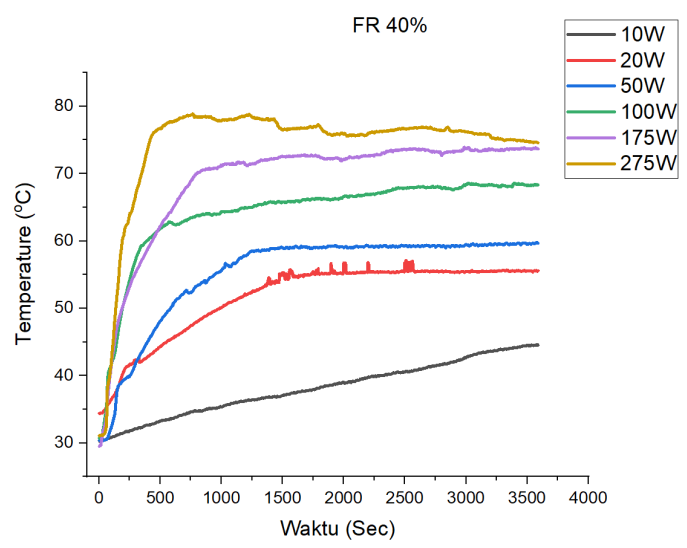

Gambar 5 Temperature evaporator terhadap waktu FR 40\%

Pada grafik terlihat bahwa kenaikan temperature pada bagian evaporator ketika startup, memiliki gradien kenaikan temperatur yang berbeda. Semakin besar beban kalor yang diaplikasikan, semakin besar pula gradien kenaikan temperatur. Selain itu untuk mencapai nilai temperatur steady, terlihat bahwa makin besar beban kalor, keadaan steady semakin cepat tercapai. Pada grafik terlihat, untuk FR 40\%, evaporator pipa kalor mencapai kondisi temperatur steady tercepat pada beban kalor $275 \mathrm{~W}$. Untuk beban kalor terkecil 10W, kondisi steady bahkan belum tercapai. Hal ini terjadi karena semakin besar beban kalor, maka penguapan semakin cepat kemudian segera mengaktifkan siklus kerja dari pipa kalor.

\section{Distribusi Temperatur Pipa Kalor}

Distribusi temperatur dengan pembacaan dinding luar pipa kalor di berbagai titik pada evaporator, adiabatik dan kondenser. Distribusi temperatur pada bagian tersebut merepresentasikan temperature dan pergerakan fluida kerja di pada pipa kalor. Pada gambar 6, grafik terlihat profil temperatur dinding pada evaporator bergerak menuju kondenser semakin menurun. Hal ini terjadi karena kalor dilepaskan pada bagian kondensor. Pada grafik tersebut terlihat semakin besar beban kalor yang diberikan ke bagian evaporator, maka perbedaan temperatur sepanjang pipa kalor semakin besar. Hal ini terjadi karena perbedaan laju penguapan fluida kerja di evaporator semakin besar dibandingkan dengan laju kondensasi fluida kerja di kondensor. Akibat perbedaan laju penguapan dan kondensasi menyebabkan temperatur di bagian evaporator terus meningkat karena fluida kerja di evaporator semakin berkurang.

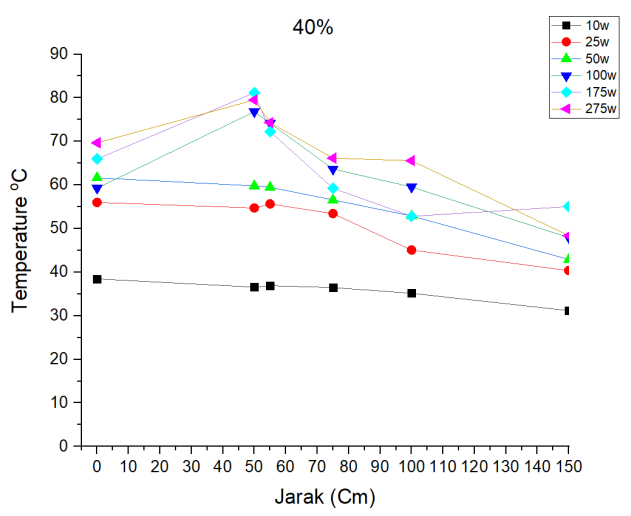

Gambar 6 Distribusi Temperature FR 40\%

Gelembung uap dapat terbentuk disekitar dinding bagian dalam evaporator saat critical heat flux. Gelembung uap mengurangi kontak antara fluida kerja yang berupa cairan dengan dinding evaporator. Akibatnya semakin banyak gelembung uap yang menempel pada dinding bagian dalam evaporator, semakin mengurangi perpindahan kalor dari dinding evaporator ke 
fluida kerja karena konduktivitas termal uap lebih rendah dari cairan. Selanjutnya, dilihat dari temperature kondensor, tidak jauh berbeda dengan temperature evaporator. Hal ini terjadi karena debit aliran cairan pendingin yang relatif kecil sehingga temperatur kondensor juga meningkat.

\section{Pengaruh Filling Ratio}

Pada Gambar 7, merupakan grafik temperature evaporator steady pipa kalor dengan variasi filling rasio, $\mathrm{FR} 40 \%, 60 \%$ dan $80 \%$. Beban kalor yang diterapkan, divariasikan pada 10W, 25W, 50W, 100W, 175W dan 275W. Pada grafik untuk semua variasi $\mathrm{FR}$, terlihat bahwa dengan naiknya beban kalor, naik pula temperature evaporator. Pada grafik menunjukkan bahwa untuk beban kalor 10W sampai 100W, temperatur evaporator semakin turun dengan naiknya FR. Kemudian dapat dilihat bahwa FR $40 \%$ menghasilkan temperatur kerja evaporator tertinggi pada beban kalor $10 \mathrm{~W}$ sampai $175 \mathrm{~W}$. Namun demikian, ketika beban kalor dinaikkan ke $175 \mathrm{~W}$, terlihat bahwa temperatur evaporator $80 \%$ lebih tinggi dari pada FR $60 \%$. Selanjutnya ketika beban kalor dinaikkan lagi ke 275W, temperatur evaporator untuk FR $80 \%$ melampaui temperatur evaporator FR $60 \%$ dan FR $40 \%$.

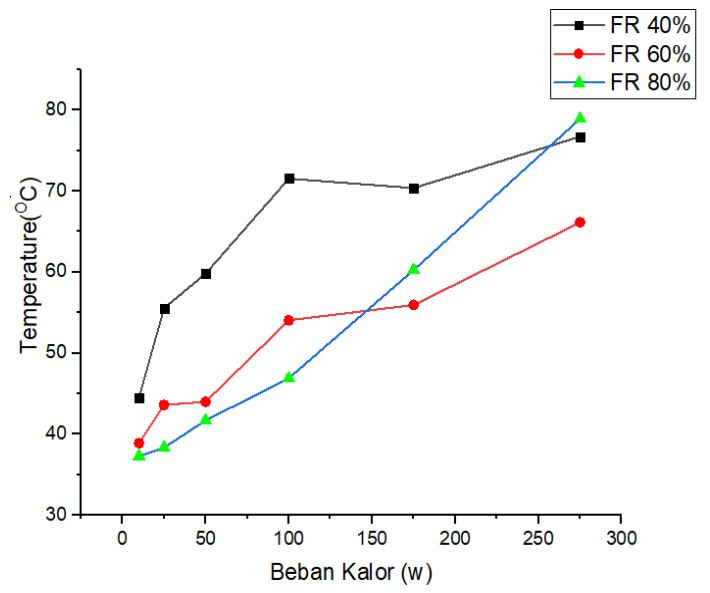

\section{Gambar 7 Temperatur Evaporator Versus Waktu}

Penomena ini bisa dijelaskan, bahwa kinerja terbaik untuk FR $40 \%$ dan $60 \%$ terjadi pada beban kalor $100 \mathrm{~W}$ hingga $175 \mathrm{~W}$. Kinerja ini diindikasikan dengan temperatur evaporator yang hampir sama walaupun beban kalor dinaikkan dari 100W ke 175W. Adapun untuk FR $80 \%$, temperatur evaporator tetap konsisten meningkat dengan naiknya beban kalor. Dari grafik dapat dilihat bahwa FR yang optimal adalah FR 60\%. Dimana pada FR 60\%, menghasilkan uap yang paling banyak, sehingga sirlkulasi fluida kerja pipa kalor berlangsung dengan baik.

\section{Analisis Hambatan Termal Pipa Kalor Pada Berbagai Filling Rasio}

Gambar 8, merupakan grafik tahanan termal pipa kalor dengan variasi filling rasio $40 \%, 60 \%$ dan $80 \%$ dengan variasi beban kalor $10 \mathrm{~W}, 25 \mathrm{~W}, 50 \mathrm{~W}, 100 \mathrm{~W}, 175 \mathrm{~W}$ dan 275W. Grafik menunjukkan tahanan termal pipa kalor semakin rendah seiring dengan bertambahnya beban kalor. Hasil ini sesuai dengan kecenderungan khas heat pipe yaitu tahanan termal menurun mengikuti kenaikan beban kalor yang diaplikasikan pada evaporator. Hal ini disebabkan oleh keuntungan penggunaan air dimana nilai merit meningkat pada beban kalor yang lebih tinggi (Setyawan et al., 2019).

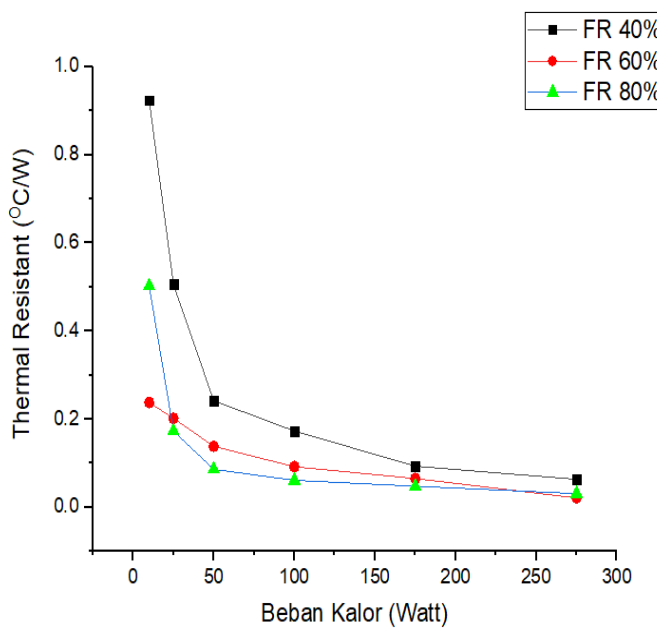

\section{Gambar 8. Tahanan Termal Pipa Kalor}

Pada pembebanan rendah, jumlah uap yang ditransport dari evaporator ke kondenser sedikit. Pada beban kalor yang lebih besar, jumlah uap yang ditransport ke kondenser semakin besar. Pada grafik terlihat bahwa FR 40\% menghasilkan tahanan termal yang terbesar diantara FR $60 \%$ dan FR $80 \%$. Pada beban kalor $25 \mathrm{~W}, 50 \mathrm{~W}, 100 \mathrm{~W}$ dan $175 \mathrm{~W}$, tahanan termal terendah terjadi pada FR $80 \%$. Namun demikian FR $60 \%$ menghasilkan tahanan termal yang juga hampir sama dengan dengan FR $80 \%$ untuk beban beban kalor 25W hingga 275W. Sedangkan untuk beban rendah 10W, FR 60\% menghasilkan tahanan termal yang paling rendah. 


\section{SIMPULAN}

Dari penelitian pipa kalor dengan berbagai variasi filling rasio FR, diperoleh beberapa kesimpulan, yaitu untuk beban kalor 10W hingga 100W, FR 80\% memberikan kinerja yang lebih baik. Untuk beban kalor yang lebih tinggi $175 \mathrm{~W}$ hingga $275 \mathrm{~W}$, FR $60 \%$ menghasikan kinerja yang paling baik dibandingkan, FR $80 \%$ dan FR 40\% yang diindikasikan dengan temperature evaporator yang lebih rendah.

Demikian pula tahanan termal pada FR $60 \%$ menghasilkan tahanan termal yang hampir sama dengan dengan FR 80\% untuk beban kalor 25W hingga 275W. Namun demikian pada beban kalor 10W, FR 60\% menghasilkan tahanan termal yang lebih rendah diantara FR40\% dan FR 80\%. Dengan demikian, dari hasil temperatur dan tahanan termal untuk pipa kalor dengan range beban kalor yang yang lebih luas, FR 60\% menghasilkan kinerja terbaik dibandingkan FR $80 \%$ dan FR 40\%.

\section{DAFTAR PUSTAKA}

Bumataria, R.K., Chavda, N.K. and Panchal, H., 2019. Current research aspects in mono and hybrid nanofluid based heat pipe technologies. Heliyon, 5(5), p.e01627.

Faghri, A., 2014. Heat pipes: review, opportunities and challenges. Frontiers in Heat Pipes (FHP), 5(1).

Huang, J., Zhou, W., Xiang, J., Liu, C., Gao, Y., Li, S. and Ling, W., 2020. Development of novel flexible heat pipe with multistage design inspired by structure of human spine. Applied Thermal Engineering, p.115392.

Putra, N., Setyawan, I. and Raditya, D., 2016. Experimental investigation on contact angle of sintered copper powder wick. In Applied Mechanics and Materials (Vol. 819, pp. 575-579). Trans Tech Publications Ltd.

Putra, N. and Septiadi, W.N., 2014. Teknologi Pipa Kalor Teori, Desain, dan Aplikasi. Jakata: UI-Press.

Ramachandran, R., Ganesan, K., Rajkumar, M.R., Asirvatham, L.G. and Wongwises, S., 2016. Comparative study of the effect of hybrid nanoparticle on the thermal performance of cylindrical screen mesh heat pipe. International Communications in Heat and Mass Transfer, 76, pp.294-300.
Setyawan, I., Putra, N., Hakim, I.I. and Irwansyah, R., 2019. Development of hybrid loop heat pipe using pump assistance for cooling application on high heat flux device. Journal of Mechanical Science and Technology, 33(8), pp.3685-3694.

Setyawan, I., 2018. Pengembangan Hybrid Loop Heat Pipe Untuk Aplikasi Pendinginan Device Berfluks Kalor Tinggi. Disertasi. Fakultas Teknik Universitas Indonesia, Depok.

Setyawan, I., Putra, N. and Hakim, I.I., 2018. Experimental investigation of the operating characteristics of a hybrid loop heat pipe using pump assistance. Applied Thermal Engineering, 130, pp.10-16.

Wahyu, D., 2016. Experimental study of heat pipe for solar collector heater. Jurnal Teknik Mesin, 6(1), pp.06-14.

Zohuri, B., 2016. Heat pipe design and technology: Modern applications for practical thermal management. Springer. 